From the above results it is concluded that oximes in the crystalline state correspond closely with the classieal oxime formula $=\mathrm{C}=\mathrm{N}-\mathrm{OH}$.

It may be a general phenomenon with the aromatic aldoximes that the syn forms are associated in dimers and the anti forms in chains, as was found for the $p$-chlorobenzaldoximes. This concept is supported by evidence from infra-red absorption spectra of syn and anti forms of some aromatic aldoximes, and offers an explanation of the curious fact that for these oximes the trans forms (syn) generally have lower melting points than the cis forms (anti).

Two of the types of molecular association found in oximes are paralleled by the dimers and chains found in the crystal structures of carboxylic acids; the intermediate form, that is, the trimers in the crystals of the symmetrical oximes acetoxime and cyclohexanone oxime ${ }^{7}$, has no counterpart in the known structures of carboxylic acids.

A detailed account of this work will be published elsewhere ${ }^{8}$.

Bodil Jerslev

Royal Danish School of Pharmacy, Copenhagen.

1 Jers]ev. B., Nature, 166, 741 (1950).

2 Merritt, L. L., and Lanterman, E., Acta Cryst., 5, 811 (1952).

${ }^{3}$ Hall, D., and Llewellyn, F. J., Acta Cryst., 9, 108 (1956).

‘ Donohue, J., J. Amer. Chem. Soc., 78, 1172 (1956).

${ }^{5}$ Bierlein, T. K., and Lingafelter, E. C., Acta Cryst., 4, 450 (1951).

- Palm, A., and Werbin, H., Canad. J. Chem., 31, 1004 (1953).

'Okaya, Y., Shimada, A., and Nitta, I., Bull. Chem. Soc. Japan, $29,210(1956)$.

- Jerslev, B., thesis, Copenhagen (1958).

\section{Spiral Crystals of Meconin}

THE growth of zinc sulphide ${ }^{1}$ and magnesium sulphate ${ }^{2}$ erystals in spiral form has recently been reported. Spiral crystals of meconin (6:7-dimethoxy-phthalide) with melting point $101-101.5^{\circ} \mathrm{C}$. (lit. $\left.102 \cdot \tilde{5}^{\circ}\right)$ ) have been isolated from an aqueous propanolic solution which had been saturated with chloroform.

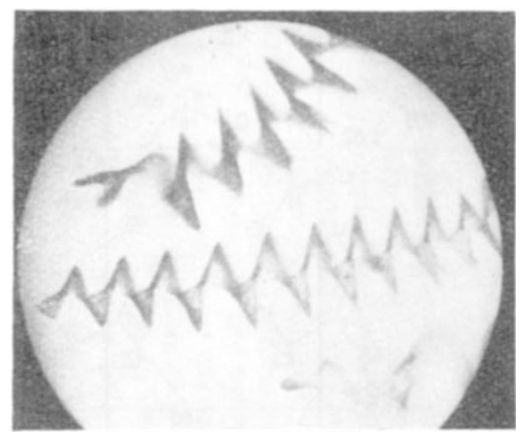

Only six spirals, 2-3.3 mm. in length, appeared together with the regular needle form. An attempt to reproduce this spiral crystal form was unsuccessful. The photograph, taken by I. MeGill, shows three crystals, the central one of which was $2 \mathrm{~mm}$. long.

\section{W. R. LOGAN}

Chemistry Department,

The Royal College of Science and

Technology,

Glasgow, C.1.

'Atdamiano, A., Nature, 179, 493 (1957).

2 Shayer, M., Nat:tre, 179, 1364 (1957).

\section{A New Metallic Layer Structure}

DURING the course of an investigation into the system manganese/mercury, I confirmed the existence of the intermediate phase $\mathrm{Mn}_{2} \mathrm{Hg}_{5}$ reported by Prelinger $^{1}$ and described its crystal habit and determined the dimensions of its unit cell2. Since then, satisfactory Weissenberg photographs have been obtained from very small crystals $(0.01-0.02 \mathrm{~mm}$. in diameter). The only systematic absences observed were $0 k l$ for $k$ odd, which lead to three possible space groups, namely, $P 4 / m b m\left(D^{5}{ }_{4 h}\right), P \overline{4} b 2\left(D^{z_{2} d}\right)$ and $P 4 b m\left(C^{2}{ }_{4 v}\right)$. Furthermore, the $h k 0$ and $h k 2$ intensities display the same trend, which is different from that of the $h k l$ intensities. If the ten mercury atoms in the cell are all placed at $z=0$ and the four manganese atoms at $z=\frac{1}{2}$, it is apparent that the geometrical structure factor for the first of the three space groups is identical for all reflexions with $l=2 n$, but the manganese contributions reverse their signs for $l=2 n+1$. This arrangement of atoms is only possible in the space group $P 4 / \mathrm{mbm}$. From packing considerations a structure could be derived which gave good agreement between the observed and calculated intensities. The geometrically derived parameters are $u=0.075$ and $v=0.206$ for the eight mercury atoms at positions $\pm\left(u r 0 ; v u 0 ; u+\frac{1}{2}, \frac{1}{2}-v, 0 ; v+\frac{1}{2}\right.$, $\left.n+\frac{1}{2}, 0\right)$ and $u=0.178$ for the manganese atoms at $\pm\left(u, u+\frac{1}{2}, \frac{1}{2} ; u+\frac{1}{2}, \bar{u}, \frac{1}{2}\right)$, the two remaining mercury atoms being situated at special positions $\left(\frac{1}{2}, 0,0\right)$ and $\left(0, \frac{1}{2}, 0\right)$. Further refinement of these parameters by Fourier methods is under way; the results will be published more fully elsewhere.

The above structure leads to a closely packed arrangement in which each mercury in the (001) planes is in direct contact with its four nearest mercury neighbours in the same plane, and with one mercury atom above and below it. Each manganese atom is also in direct contact with six mercury atoms-for example, $A, B$ and $C$ in Fig. 1 and the atoms directly above them-and fits exactly into the vacant site between them.

The new metallic layer structure displays a remark. able similarity to that of tetramminopalladous chloride monohydrate, $\mathrm{Pd}\left(\mathrm{NH}_{3}\right)_{4} \mathrm{Cl}_{2} \cdot \mathrm{H}_{2} \mathrm{O}$ and its platinum isomorph ${ }^{3}$. The two extra (heavy metal) atoms per unit cell of the complex occupy the special positions $(0,0,0)$ and $\left(\frac{1}{2}, \frac{1}{2}, 0\right)$, which are unoccupied in $\mathrm{Mn}_{2} \mathrm{Hg}_{5}$. Although it would seem rather surprising that an alloy crystallizes with basically the $\operatorname{sam} \theta$ atomic arrangement as a co-ordination complex, the close packing in the structure of $\mathrm{Mn}_{2} \mathrm{Hg}_{6}$ emphasizes its typically metallic character.

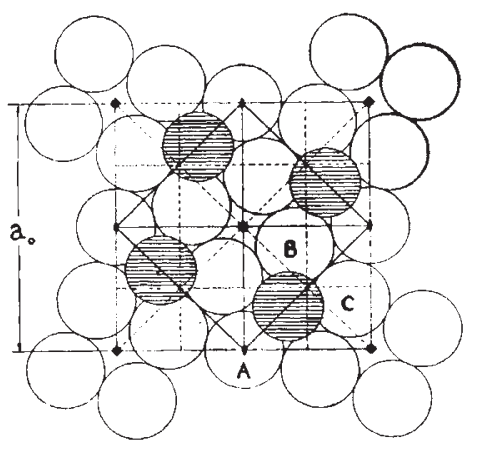

Fig. 1. Projection on (001) of the structure of $\mathrm{Mn}_{3} \mathrm{Hg}_{3}$ with two formula units per unit cell. The atomic radi taken are $r \mathrm{H}_{\mathrm{g}}=$
$\mathbf{1} \cdot 50 \mathrm{~A}$. and $r \mathrm{Mn}_{n}=1.35 \mathrm{~A}$. 